\title{
Denise Andrey Geometric Methods of the 1500s Mirko Galli for Laying Out the Ionic Volute
}

\section{Introduction}

Volutes, a distinguishing feature of the Ionic order, are the double curls in the form of spirals on either side of the Ionic capital. In the Renaissance, the Ionic volute was the object of study for architects who were concerned with the development of the new theories of architectural forms. In addition to studies of its proportions, research focused on the search for a sure and elegant method for laying out the volute. The point of departure for the elaborate theories were the ruins of buildings from the classical era and the treatise by Vitruvius. Authors Denise Andrey and Mirko Galli compare and contrast three methods by Sebastiano Serlio, Giuseppe Salviati and by Philandrier for laying out the Ionic volute.

The capital of the Ionic column is characterized by the presence of two spiralling curls on its sides, called volutes. They are part of the complex system of architectonic forms known by the name of orders, one of the fundamental principles of Western architectural culture of the last six centuries.

In architectural treatises compiled from the Renaissance up through the last century, the study of the Ionic volute has been set forth and debated innumerable times, and many diverse solutions have been elaborated and propagated, so much so that the theme of the correct method for laying out the volute retained a significance that was far from marginal up through the nineteenth century. ${ }^{1}$ The debate that surrounded the form of this element began between the $1400 \mathrm{~s}$ and the 1500 s, and arose from the difficulty of interpreting a brief passage in the Roman architectural treatise of Vitruvius. ${ }^{2}$ This difficulty posed problems of a practical as a philological nature: it was not only a matter of establishing the correct interpretation of an antique and authoritative text, but - much more importantly - the object was to develop (based on the authority of Vitruvius) a method for laying out the volute that could then be put into practice in the construction methods of the 1500s, thus permitting the general use of the Ionic order.

Our interest revolves around the characteristics of three methods for laying out the voluteeach of which would subsequently enjoy great notoriety-developed by three authors during a relatively brief period at the beginning of the 1500s. These methods have been studied with regards to their geometric and mathematical characteristics, beginning with the original texts in which they are described. First they were redrawn, in order to study how straightedge and compass were utilized, then the mathematical properties that underlie them were studied, and finally their eventual classification according to types of spiral were verified.

\section{The Ionic Order and the Cultural Heritage of Antiquity in the Renaissance}

The sources to which the architects of the Renaissance refer in order to develop their systems of the orders are two: on the one hand, Vitruvius and the instructions set forth in his treatise; on the other hand, Rome and the ruins of the Roman Empire scattered throughout Italy. The study of Vitruvius's text and the survey of the ruins of Roman architecture still existent evolved in parallel with the development of contemporary building practices of the Renaissance, at a time 
when architects sought to introduce as many classical references as possible into their building programs.

The study of ruins was concentrated mainly on the ruins of Rome itself, already well known to the architects and artists of the 1400s. Initially, their knowledge was restricted to the visual observation and to studies in situ, but the second half of the 1400 s saw the beginnings of surveys and systematic studies, and their eventual publication, ${ }^{3}$ from the moment that drawings became an instrument for the faithful representation of forms and the practice of orthogonal projection became current [Recht 2001: 135]. The effect of the study and publication of surveys is very noticeable in the development of architectural treatises. During the 1400s, writings about architecture are above all literary exercises, lacking descriptions that could be of immediate application by architects dealing with practical building tasks [Kruft 1998: 79 ff]. Beginning with the first years of the 1500s, we find instead a whole series of authors whose writings were intended to furnish the architect with the practical information that he requires to design and build, illustrating for him the rich formal vocabulary derived from the classical cultural heritage, resulting in a comparison between the descriptions provided by Vitruvius and the Roman ruins. From this moment, the study of the antique is undertaken with the intent to draw from it useful instructions for design and concrete realization of new works [Johst 1997]. During this second phase the problems such as laying out the volute of the Ionic capital are undertaken and debated in depth, since their resolution is the essential premise for the development of design and construction practice.

The Ionic order, with its characteristic capital, is one of the modi, that is, of the architectural styles, described by Vitruvius in his treatise of architecture, who indicated it as a middle ground between the Doric and the Corinthian, at once severe and delicate [Vitruvius 1997: III]. The capital, of which the spiral volutes are the distinguishing characteristic, has its origins in the Greek; its forms were introduced into the Roman architecture of the classical period by the Hellenistic influence. ${ }^{4}$ The Ionic order, little used at the beginning of the Renaissance (because it was less distinguished than the other two) was used progressively more often during the second half of the 1400s, both as an intermediate order in buildings with several floors and in its own right in buildings that were both sober and elegant [Forsmann 1988, esp. chap. II].

The discussion in Vitruvius's treatise that regards the Ionic order and its various parts (including the spiral volutes) is concentrated on a brief passage of text in which Vitruvius describes the Ionic volute as a curve in the form of a spiral, which, starting at a point immediately under the abacus (the upper, flat, part of the capital upon which rests the architrave) winds in a series of turns until it joins a circular element known as the "eye". The center of the eye is situated on a vertical line, parallel to the cathetus, the line that descends vertically to the extreme point of the abacus [Vitruvius 1997: III, 256]. The Vitruvian text furnishes some basic rules that are very clear, but it is more difficult to interpret the real laying out of the curve of the volute, above all beyond the first turn. Vitruvius only furnishes proportional ratios, and no concrete dimensions. The base rules indicated in his text, which we have also indicated in Fig. 1, are:

- Total height of the volute: 8 units;

- Diameter of the eye: 1 unit;

- Above the center of the eye: $41 / 2$ units;

- Below the center of the eye: $31 / 2$ units. $^{5}$

Vitruvius then simply indicates that the volute is laid out by means of quarter-circles, using a compass, ${ }^{6}$ starting with the outermost point, up to arriving at the conjunction with the eye, 
decreasing by one-half unit the distance from the center of the eye at each successive quarter-circle set out. The text does not indicate precisely how many quarter-circles are necessary to complete the volute, nor does it indicate the position of its center, nor does it indicate how many turns must be completed in all. If the diminution of the radius of one-half unit every quarter-circle remains constant, it is evident that eight quarter-circles are sufficient to reach the eye, ${ }^{7}$ that is, two complete turns, a detail that is missing from the text. Vitruvius makes reference in his text to a figure that has not come down to us. The lack of the drawing (which probably was only an elementary geometrical scheme ${ }^{8}$ ) introduces an element of the unknown (only apparently marginal) in the description of the volute beyond the first turn, furnishing for Renaissance theorists both a starting point and a justification for the development of their own methods.

To this unknown element were subsequently added, as the surveys of the Roman ruins proceeded, the contradictions between the surveys and Vitruvius's treatise. In the case of the Ionic capital, measuring and surveys make evident the fact that the capitals possess volutes in which the distance between the turns diminishes progressively towards the center and in which the turns are usually three, partly contradicting, or at least rendering more obscure, Vitruvius's descriptions. Further, between capital and capital there are significant differences in measurements and forms. ${ }^{9}$

The methods developed during the Renaissance represent a reaction of the Renaissance culture to this situation of uncertainty and contradiction. Each author goes in search of his own model of the Ionic capital, derived from his own personal critical interpretation of the literary and archaeological sources, using drawing as an instrument for formal analysis. ${ }^{10}$ The aim of the research into antiquity is progressively transformed from mere imitation to the search for and invention of design rules for application in actual projects [Günther 1994, 266].

\section{The Design of the Volute}

Drawing the Ionic volute involves distinguishing a graphic method for laying out a curve, which from a smaller circle with a given dimension one makes a certain number of turns towards a larger circle, also of a given dimension, which is concentric with respect to the first. This represents the mathematical definition of a spiral segment. ${ }^{11}$ The solutions presented in the architectural treatises of the 1500 s all have in common the compass as the instrument of the fundamental drawing, and the arc of the circle as the basis of the laying out of the volute. Three methods in particular would become well-known and would be reproduced in successive treatises:

- the method of semi-circular arcs of Sebastiano Serlio (1537);

- the method of quarter-circle arcs of Giuseppe Salviati (1552);

- the method of eighth-circle arcs of Giullaume Philandrier (1544).

In order to compare these constructions we have chosen to redraw them according to the instructions in the original texts, utilizing a modern program for assisted architectural drawing. This procedure presupposes on the one hand the accurate comprehension of the method, annulling errors of draftsmanship and approximation; on the other hand it allows us to extract directly from the drawing a set of numeric data that is highly precise, which we will use to set forth a first series of observations, on the basis of which we will proceed to the mathematical analysis of the construction. 


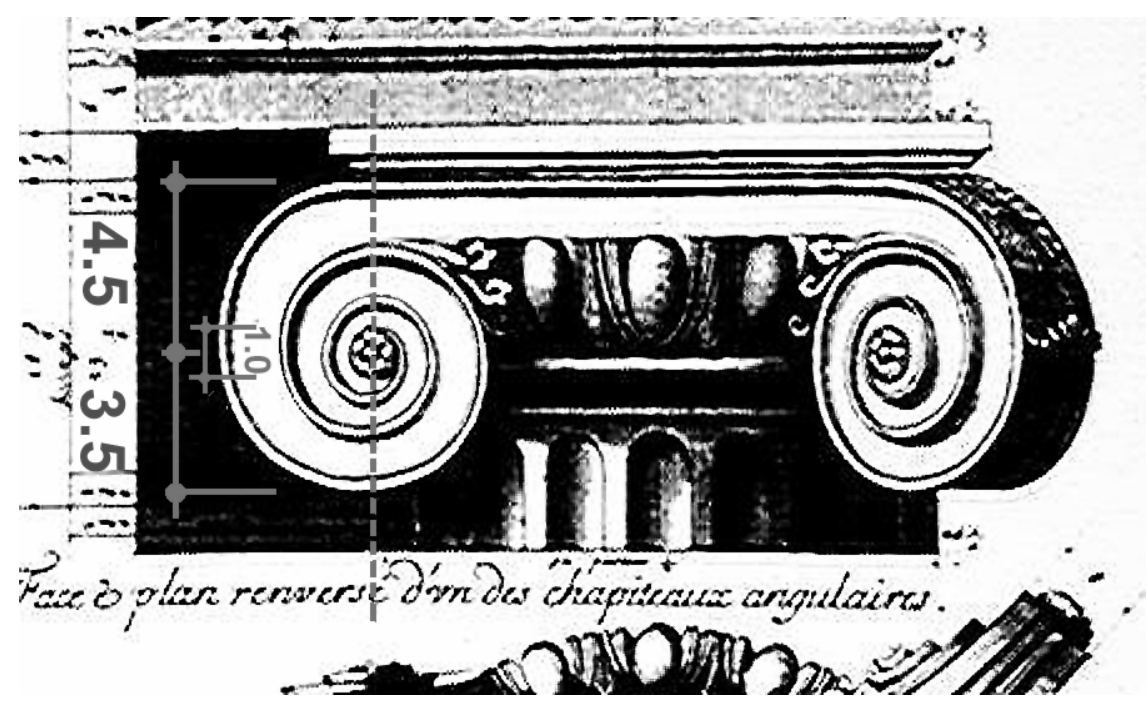

Fig. 1. The Ionic capital of the Temple of Fortuna Virilis, Rome, with descriptions of its principle parts and of the proportional ratios indicated by Vitruvius. Detail of the plate illustrating the Ionic capital, from A. Desgodetz, Les Edifices Antiques de Rome, Paris 1682

\section{Serlio}

Sebastiano Serlio published Book IV of his architectural treatise in $1537 .{ }^{12}$ The Serlian method takes the ratios indicated by Vitruvius, then distinguishes six points (the centers where the compass is placed) dividing the vertical diameter of the eye into six equal parts and numbering the points alternating between upper and lower, beginning with the uppermost. The volute is constructed by laying out a series of semicircles starting from the point under the abacus and centering the compass in the point numbered 1 , moving then after each semicircle the point of the compass to the next numbered point, up to point 6 . Each successive semicircle has thus a radius that is less than the preceding one by, respectively, $-1,-5 / 6,-4 / 6,-3 / 6,-2 / 6$ units. Since the reductions are five in all, with a last semicircle of radius $4 / 6$ units (the center of which is point 6 ), the volute closes upon the eye.

In order to describe the numerical order of the centers, which is the most important information contained in Serlio's method, he refers explicitly to a figure ${ }^{13}$ in which, however, the numeration is indicated in a somewhat dubious, if not erroneous, manner (rather than 1-3-5-nit6-4-2, which is correct, the drawing indicates nil-1-3-5-6-4-2, where nil is the point with no number). The error is repeated in many successive Italian editions in which the original xylograph has been re-used, and was corrected only with the European editions of the treatise. ${ }^{14}$ Initially disconcerted (since the method is famous and none of the sources that we consulted remarked any doubt as to the numeration), by proceeding by trial and error, we were able to both verify the error and ascertain the consequent correct numeration. It is surprising, however, that such an important illustration was only corrected in much later editions realized outside Italy, ${ }^{15}$ especially considering that Serlio's treatise was the first richly illustrated treatise, in which the drawings were fundamental elements, while the text itself is reduced to captions. 

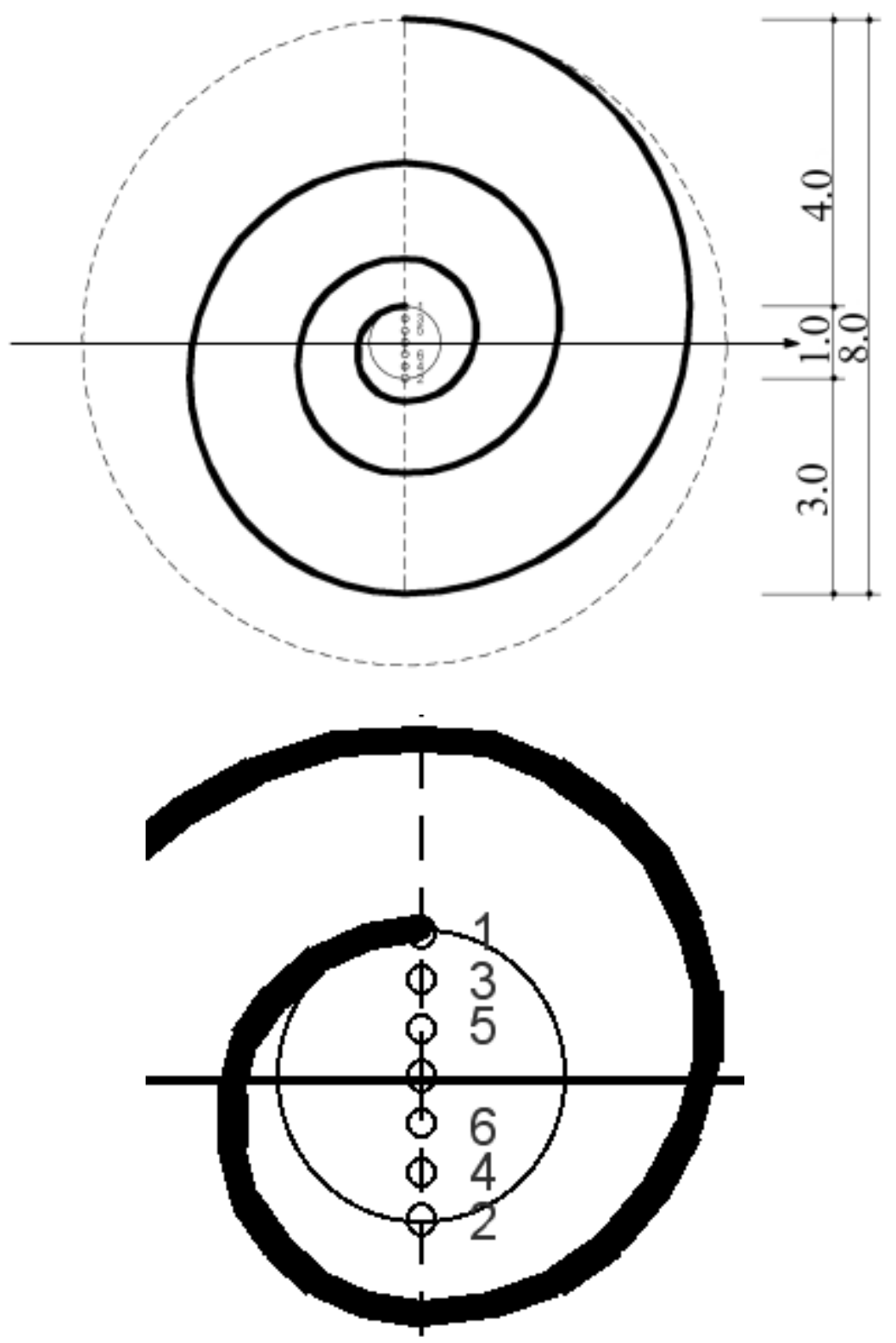

Fig. 2a (above). The Ionic volute of Sebastiano Serlio. Fig. 2b (below). Detail of the eye. Drawings by the authors

The volute drawn by Serlio has the characteristic of making three complete turns before closing on the eye. The method of six points is very ingenious in its simplicity, and probably owes something to Leon Battista Alberti, who in his De re aedificatoria, published in 1483, proposes 
construction the volute by semicircles, alternately centered in points above and below the eye ${ }^{16}$ without, however, furnishing a figure. ${ }^{17}$

\section{Salviati}

In 1552, Venetian painter Giuseppe Salviati published a pamphlet in which he illustrated a method for the construction of the volute that he invented, which would subsequently become very famous, as it was republished a multitude of times.

Salviati's volute is constituted of twelve quarter-circles, the centers of which are situated inside the eye, along the diagonal of a square that is inscribed both within the and within a larger square, which is in its turn circumscribed by the eye and rotated $45^{\circ}$ with respect to the inner square. The diagonals of the inner square are divided into six equal parts, resulting in the identification of a total of twelve points. Numbered progressively from 1 to 12 clockwise from the exterior to the interior, these are the centers of the respective quarter-circles that are laid out as the method proceeds, the point of the compass moving each time to the next successive center. The method is notable for its simplicity and formal elegance, designed for those familiar with drawing.

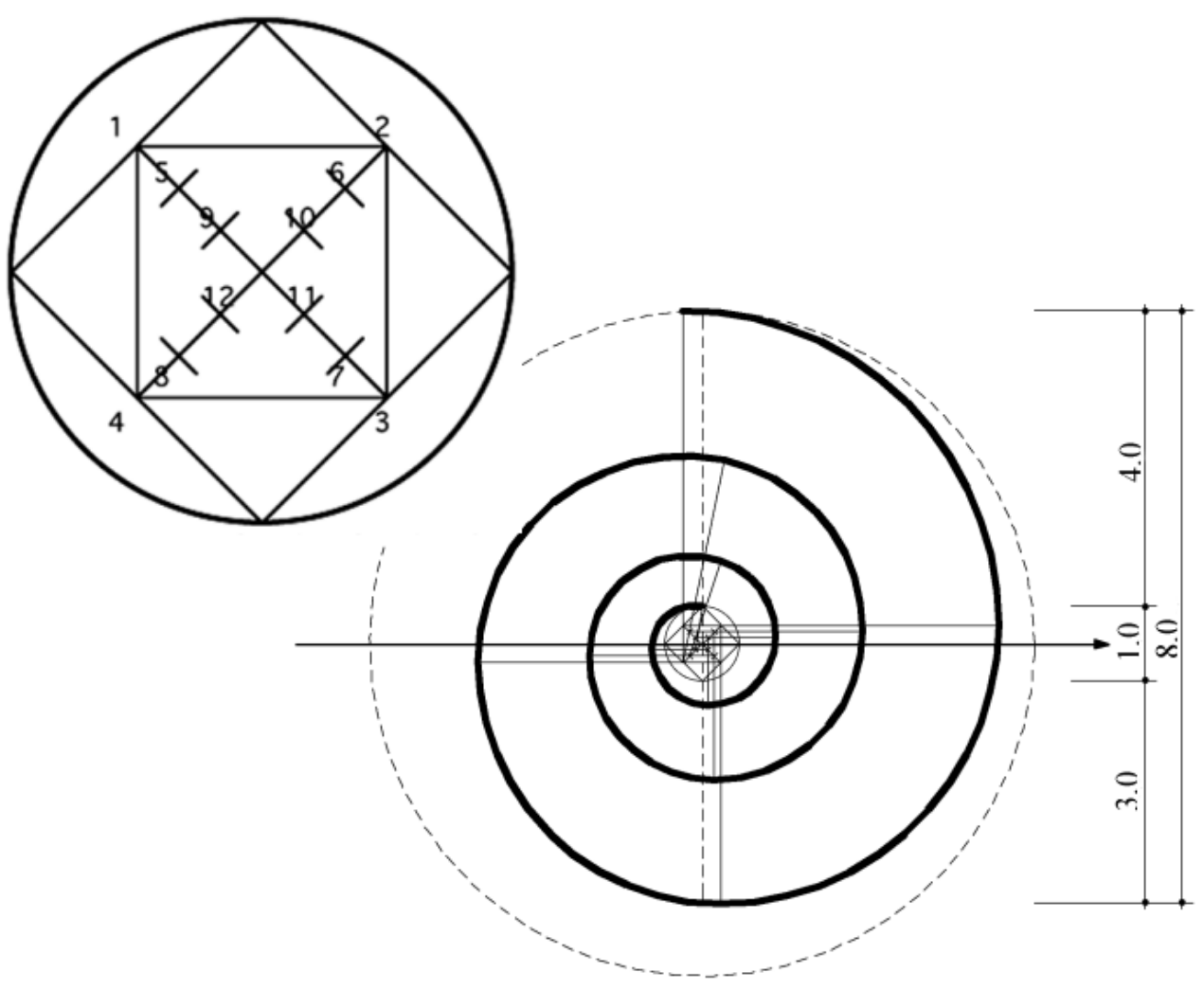

Fig. 3. The Ionic volute of Giuseppe Salviati. Drawing by the authors. Upper left: enlargement of the eye with the positions of the centers 
Salviati [1522] writes of having rediscovered the method after undertaking a precise geometric study and starting from a simple enough observation. If, as Vitruvius indicated, after a quarter turn the distance of the center diminishes by one-half unit, then if only an eighth of a turn is made, the distance of the center should diminish by only one-quarter unit. Fixing these three points (the initial, that of the eighth turn, and that of the quarter turn), he draws by means of them the segment of a circle, using, as he clearly indicates in his text, "the fifth proposition of the fourth [book] of Euclid," that is, the theorem that establishes how through any three distinct points there can pass only one circumference.

The Euclidean text in effect deals with the problem of circumscribing a given triangle with a circle, and is therefore equivalent to the determination of a center of a circumference of which three points are known. Salviati brings to light in any case a problem (which will be partially evaded by the successive propagators of his method): two successive centers must turn out to be aligned with the point of contact between their respective circular arcs. ${ }^{18}$ If this doesn't occur, the curve appears as though "broken" and the volute is not a smooth curve. Here again Salviati makes explicit reference to the Elements of Euclid. In the text he refers to the terza decima propositione [Salviati 2000: 106], but the reference is imprecise, as it does not mention which book. The proper attribution is to the thirteenth of Book III, in which Euclid demonstrates that a circle cannot be tangent to another at more than one point. In the proof of this proposition is used the eleventh proposition, in which Euclid proves that the point of contact between two circles and their two respective centers are on the same straight line. This is the true reference of Salviati, even if its geometric significance becomes clear only when it is used by Euclid in the proof of the thirteenth proposition. This can all be seen clearly in Fig. 3, in the transition from the outermost points to those within the square, where we have laid out as well the lines that unite two successive centers.

Since Vitruvius does not indicate the diminution of the volute beyond the first turn, and since, maintaining the diminution of one-half unit each quarter-turn, the volute has only two windings with regular intervals between the turns, Salviati proposes for the second turn a diminution of one-third unit every quarter turn, and for the third turn a diminution of one-sixth unit for each quarter turn, proceeding then to the determination of all the centers, formulating thus his rules of construction [Salviati 2000: 106].

The method of Salviati would be made universally known by Vignola [1562], Palladio [1570], and Scamozzi [1615], who present it, however, in a simplified form. The reflections of Salviati on the discontinuity of the curvature of the transitions between the first and the second turn and between the second and the third turn are no longer made evident. ${ }^{19}$

\section{Philandrier-Dürer}

French humanist Guillaume Philandrier set forth a method for laying out the volute in his famous Annotations to Vitruvius's text, published in $1544 .^{20}$ Based on a previously published construction by Dürer ${ }^{21}$ for generic spirals, which Philandrier adapted to the Ionic volute, the method became famous in its own right, and was later reprised by Vignola, who set it next to Salviati's method, presenting it as a valid alternative.

To lay out Philandrier's volute, it is necessary to execute a preparatory drawing of a right triangle $\mathrm{ABC}$ with base $31 / 2$ units and height $41 / 2$ units. The eye is centered in the right angle C. Vertex A is connected with the point of intersection between cathetus BC and the eye. An arc is drawn by centering the compass in $\mathrm{A}$ and opening it equal to $\mathrm{AC}$. The segment of the arc 
between the hypotenuse and the segment previously drawn is divided into 24 equal parts. The points thus obtained are projected with the center at $\mathrm{A}$ on cathetus $\mathrm{BC}$, distinguishing 24 points.
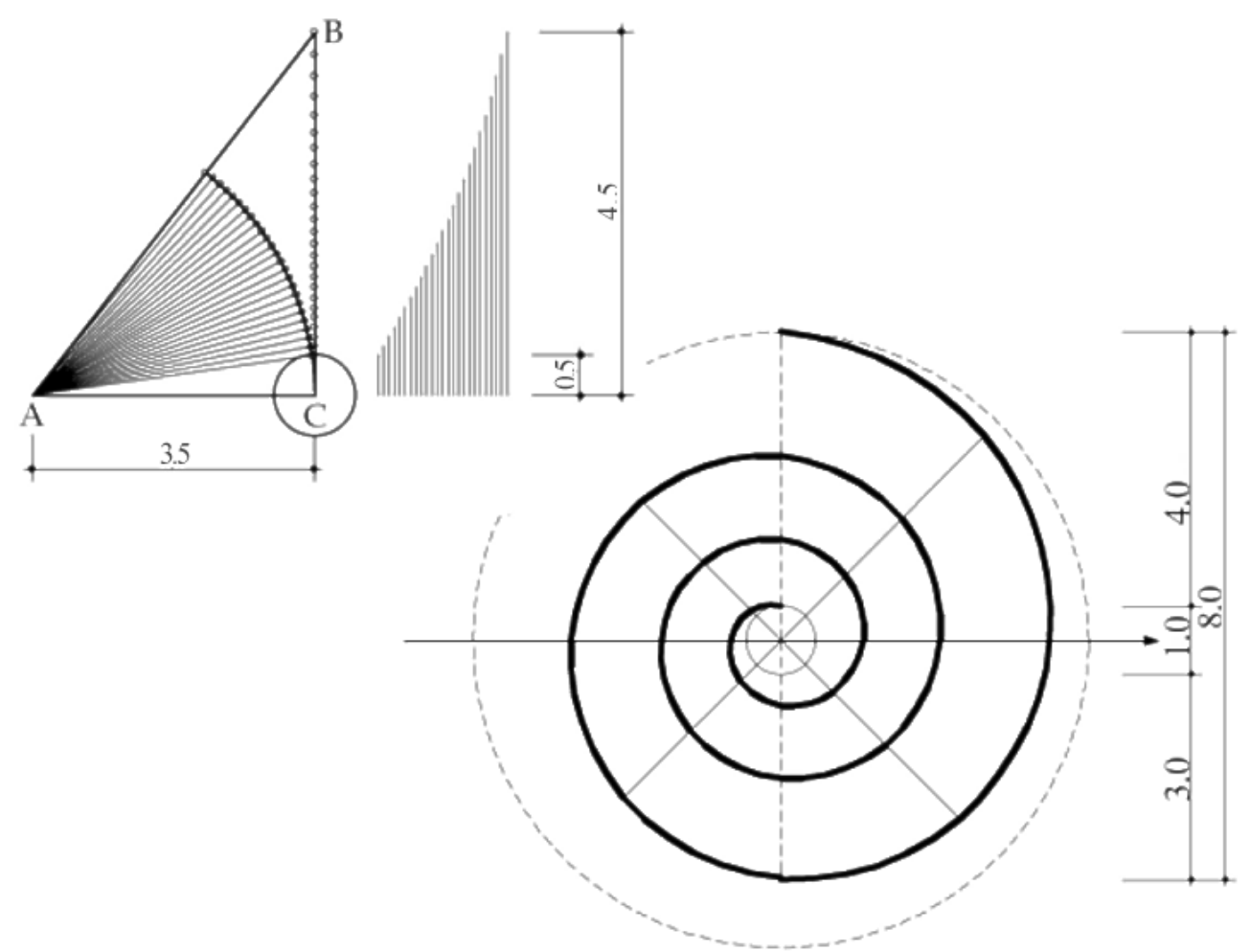

Fig. 4. The Ionic volute of Guillaum Philandrier. Drawing by the authors. In the upper left, the preparatory drawing.

These points are traced onto the main drawing, along a series of lines set out starting with the center of the eye at $45^{\circ}$ intervals, and determine the 24 points of the volute. The points are joined with circular arcs, for which, however, Philandrier indicates neither the precise locations of the centers nor a way of determining these centers. It is obvious that they can be found using the Euclidean method already discussed by Salviati. The result is a very rounded volute, which closes on the eye after three turns.

Philandrier explicitly cites Alberti, Dürer, and Serlio as his predecessors in the study of Ionic volutes [Lemerle 2000, $156 \mathrm{ff}$ ], without, however, furnishing details. Actually, Dürer's method is already quite refined and allows diverse spirals to be drawn very easily. Dürer was interested in the problem of laying out spiral curves with geometric methods that differ from those using circular arcs, and he was not interested in the Vitruvian problem of finding the centers. The circular arcs that Philandrier says he uses to connect the points found (Dürer doesn't provide instructions regarding this) are in any case marginal elements. The generating idea is completely different from the other two methods discussed above. 


\section{Mathematical Characteristics of the Methods}

It can be noted right away that within a very limited time span there arose almost contemporaneously a very simple method [Serlio 1537] that can be executed in six successive steps, and methods that are rather complex [Salviati 1552; Philandrier 1544], which require many more steps and for which it is necessary to command a great deal of drafting skill as well as at least a minimum knowledge of elementary geometry. The three methods maintain the principle proportions described by Vitruvius, but all describe a volute with three turns of an increasing distance (from the interior towards the exterior) between the turns. We shall seek to make evident certain common characteristics and peculiarities of the three methods presented here, by superimposing the three constructions.

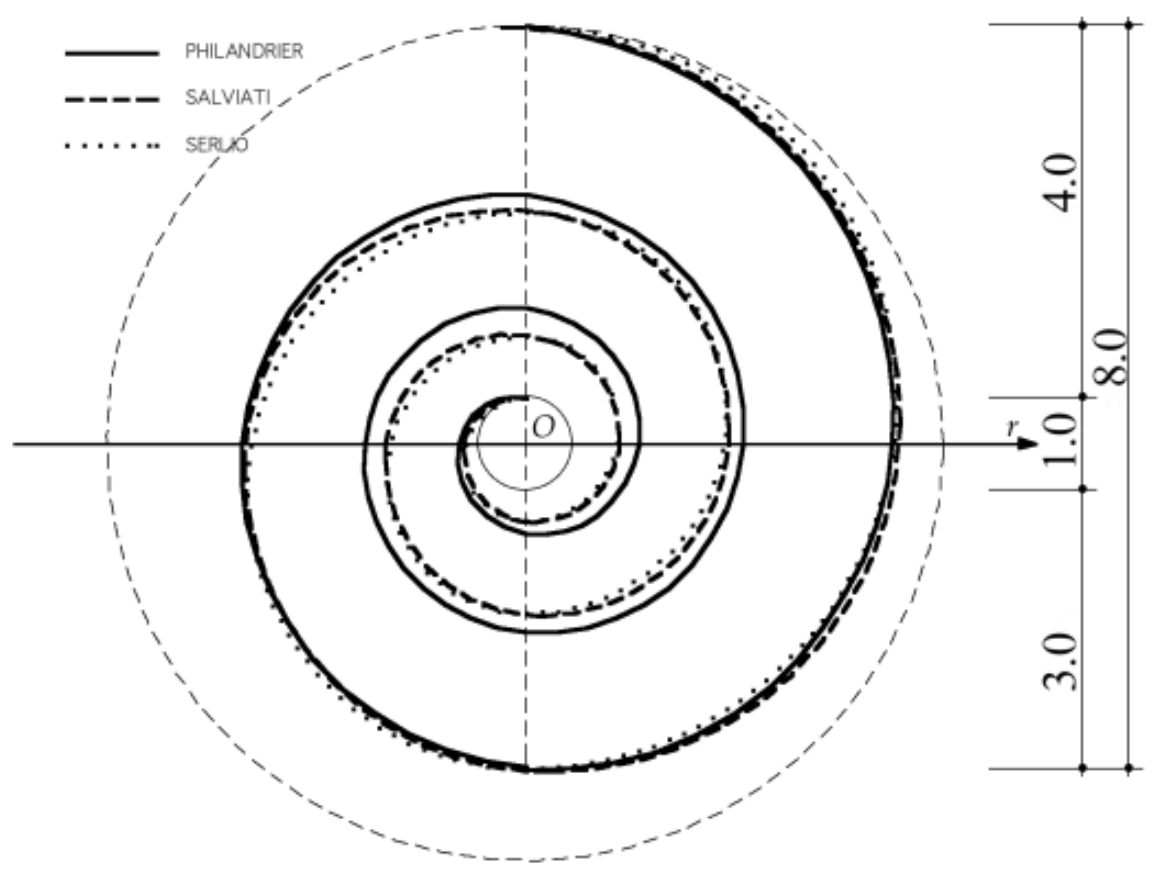

Fig. 5. The three methods compared. Drawing by the authors

The difference in process between the Serlian volute and that of Salviati is actually minimum and the two volutes coincide in many points when superimposed. If we observe them separately we have the impression that the Serlian volute leans rather to the right, but this is actually an optical effect. The volute of Philandrier differs from the other two in a fairly clear way, especially in the second, larger, turn, and reaches the eye only with an accelerated final turn.

We have composed a table of values of fullness of angle $\alpha$ (in radians) and the length of the radii $r(\alpha)$ in function of the angle for a series of common points. By radius we mean the distance of the points of the volute from center $\mathrm{O}$ of the system of polar coordinates. The values of $r(\alpha)$ were measured directly from the computer drawing, with an approximation to three decimal places. ${ }^{22}$ It should be recalled that we are dealing with a graphic method; an algebraic approach is 
not interesting a priori, but only if the constructions show interesting characteristics. In keeping with the construction processes involving semicircles, quarter circles and eighth circles, we have surveyed six points for Serlio, twelve for Salviati, and twenty-four for Philandrier. We should note that our convention was that the volute should turn from the eye outward, that is, the distance from the eye increases as the value of $\alpha$ increased (Table 1).

\begin{tabular}{|c|c|c|c|}
\hline \multirow{2}{*}{$\begin{array}{c}\text { Fullness } \\
\text { Angle } \\
\alpha \\
\end{array}$} & \multicolumn{3}{|c|}{$\begin{array}{c}\text { Radium length } \\
\mathrm{r}(\alpha)\end{array}$} \\
\hline & Serlio & $\begin{array}{c}\text { Dürer- } \\
\text { Philandrier }\end{array}$ & Salviati \\
\hline$\pi / 2$ & 0,500 & 0,500 & 0,501 \\
\hline $3 \pi / 4$ & & 0,615 & \\
\hline$\pi$ & & 0,731 & 0,668 \\
\hline $5 \pi / 4$ & & 0,849 & \\
\hline $3 \pi / 2$ & 0,833 & 0,968 & 0,836 \\
\hline $7 \pi / 4$ & & 1,090 & \\
\hline $2 \pi$ & & 1,214 & 1,004 \\
\hline $9 \pi / 4$ & & 1,341 & \\
\hline $5 \pi / 2$ & 1,167 & 1,471 & 1,177 \\
\hline $11 \pi / 4$ & & 1,605 & \\
\hline $3 \pi$ & & 1,742 & 1,511 \\
\hline $13 \pi / 4$ & & 1,884 & \\
\hline $7 \pi / 2$ & 1,833 & 2,031 & 1,846 \\
\hline $15 \pi / 4$ & & 2,184 & \\
\hline $4 \pi$ & & 2,342 & 2,181 \\
\hline $17 \pi / 4$ & & 2,508 & \\
\hline $9 \pi / 2$ & 2,500 & 2,682 & 2,518 \\
\hline $19 \pi / 4$ & & 2,864 & \\
\hline $5 \pi$ & & 3,056 & 3,018 \\
\hline $21 \pi / 4$ & & 3,259 & \\
\hline $11 \pi / 2$ & 3,500 & 3,475 & 3,520 \\
\hline $23 \pi / 4$ & & 3,704 & \\
\hline $6 \pi$ & & 3,950 & 4,021 \\
\hline $25 \pi / 4$ & & 4,215 & \\
\hline $13 \pi / 2$ & 4,500 & 4,500 & 4,500 \\
\hline
\end{tabular}

Table 1. Three constructions compared

Our next step was to transfer the data from the table to a Cartesian graphic, with the values of on the abscissa ( $x$-axis) and the volutes of $\mathrm{r}(\alpha)$ on the ordinate axis ( $y$-axis). The Cartesian representation, in contrast to the polar representation (that is, the drawings executed previously), allow us to visualize more clearly how the distance of the volute increase from the eye's center. 
This graphic representation confirms that the length of the radii of the volutes of Serlio and Salviati differ very little from one another; shown in Graph 1, they turn out to be almost perfectly superimposed.

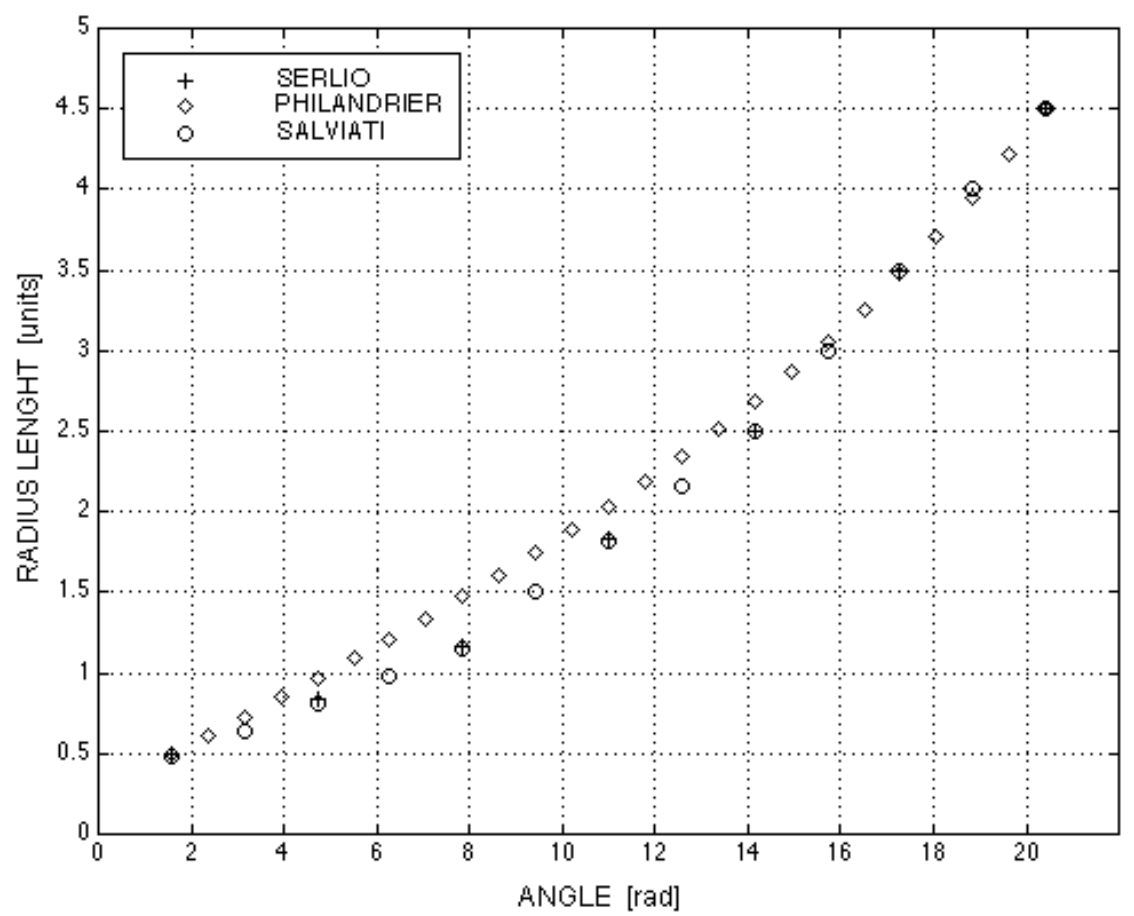

Graph 1. Three constructions compared. Drawing by the authors

The rate of increase of the radii of the volute of Philandrier-Dürer differs from the other two in the first two turns. It has an initial growth that is much more regular, even if not linear, and is therefore more accelerated as it increases.

The way in which the radii increase can help us to understand if curves that are interesting from a mathematical point of view are hidden within these three systems, and if it is worth verifying whether or not these volutes correspond, approximately or rigorously, to known equations for spirals.

In the diagram in Graph 2 we have represented the increase (the difference between consecutive radii) of the radii of the volutes.

Graph 1 shows clearly how the increases in the radii of the volutes of Serlio and Salviati differ for each successive turn. In contrast, the increase of the radii is almost constant on the interior of each turn. The equation of a spiral curve in which the increase of the distance from center $\mathrm{O}$ is constant is that of an Archimedean spiral, $r(\alpha)=a \alpha+b$ ( $a, b$ real numbers). Graph 2 clearly shows how each turn of the two volutes is like a truncated Archimedean spiral, which can be defined by means of an equation of this type with different $a$ and $b$ parameters. 


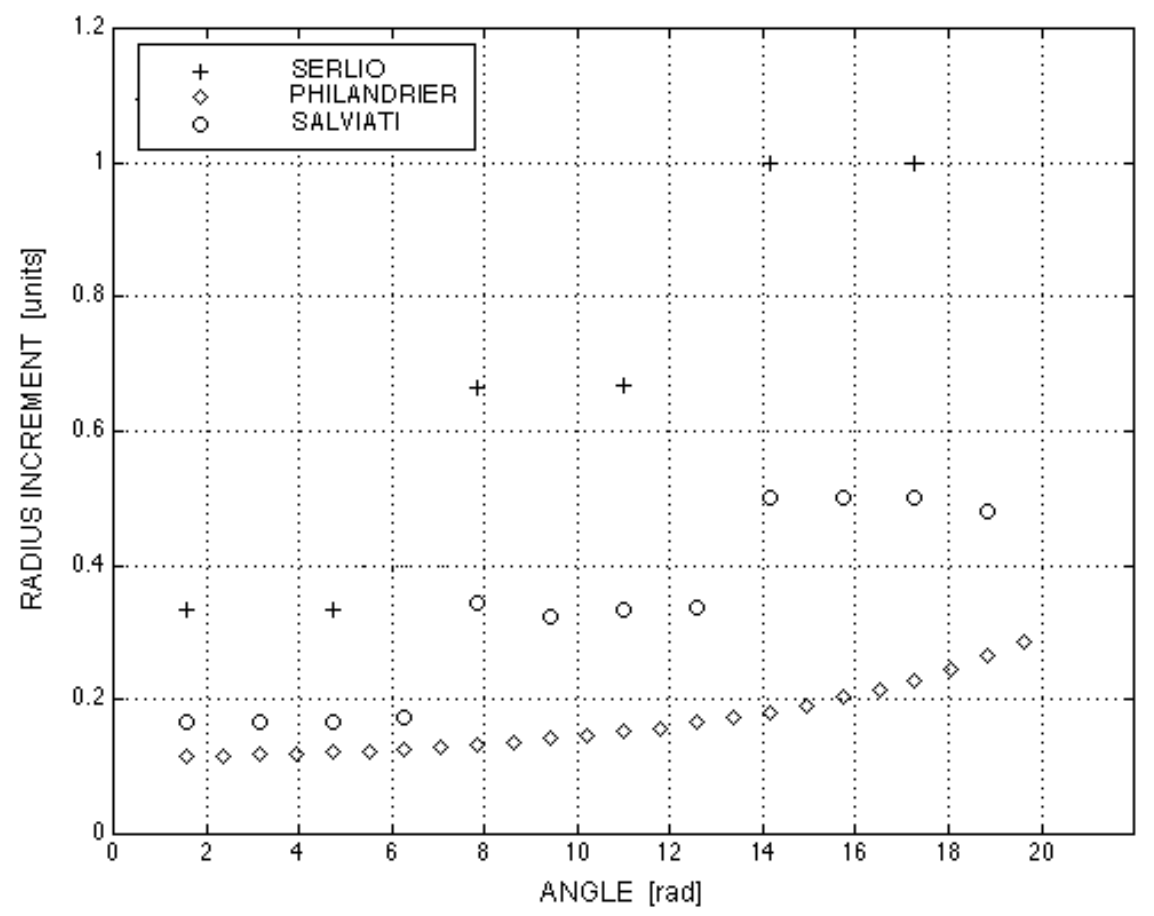

Graph 2. Increase of the length of radii. Drawing by the authors

Graph 1 and Graph 2 show that the search for a correspondence between single equations of known spirals and the curves drawn by Serlio and Salviati is relatively meaningless. Graph 1 indicates that every hypothetical curve capable of approximating with a greater or lesser degree of precision the points of Serlio and Salviati must have this characteristic: its growth (by our convention the volute grows from the eye to the exterior) should be constant and convex in the interval between $\pi / 2$ and $13 \pi / 2$ (the distance of the turns increases as it goes further away from the eye). The number of possible equations that satisfy this condition is infinite. For example, it is possible to determine parameters $a, b$, and $c$ of a second-degree polynomial function $r(\alpha)=a \alpha^{2}+b \alpha+c \quad(a, b, c$ real numbers) in such a way that it closely approximates the two constructions examined. In this case we find ourselves with a parabolic spiral. ${ }^{23}$ Further, nothing prevents us from considering polynomials of greater than the second degree. The equation $r(\alpha)=a e^{\alpha b}+c$ ( $a, b, c$ real numbers) of the logarithmic spiral corresponds to the characteristics of growth and convexity indicated and by means of the correct choice of parameters $a, b$, and $c$ can approximate the points called for.

The situation with Philandrier's volute is different. Graph 2 shows a progressive increase in the radii, but not in steps. The construction does not appear to be composed of distinct parts, and it is interesting to try to understand if it can be more or less closely approximated by some type of spiral.

42 Denise ANDREY AND MirKo GALLI - Geometric Methods of the 1500s for Laying Out the Ionic Volute 
In the original treatise by Dürer, the construction appeared after the method for constructing the Archimedean spiral, as a variant of it, to be used when the object is to construct spirals that become ever more compressed towards the center. Its construction, adopted by Philandrier for the Ionic volute, is in fact, in contrast to those of Serlio and Salviati, constructed by points which are connected by circular arcs, which, as Dürer noted, can even be drawn freehand. Dürer's procedure is much more generalized: the treatise presented a spiral constructed from twenty-four points which could be divided either by twelve radii distributed in two turns, or by eight radii distributed in three turns - thereby keeping open the option of the number of turns in which the volute must close. Further, the number of fixed points of the layout can be increased at will, increasing the number of the subdivisions of the arch in the triangle (but requiring then the layout of a greater number of circular arcs that are increasingly smaller to connect the points). Dürer himself further indicated that it would be possible to construct a spiral that narrowed or widened towards the center by varying the inclination of the cathetus of the triangle, transforming the angle from right to obtuse. Dürer, who was not looking for a method of constructing an Ionic volute, is principally interested in the construction of spirals. Thus, the construction propagated by Philandrier is a particular case, applied to the Ionic volute, of a whole series of possible spirals.

Completing the preparatory construction in Fig. 6 with some supplementary instructions allows us to make some observations.

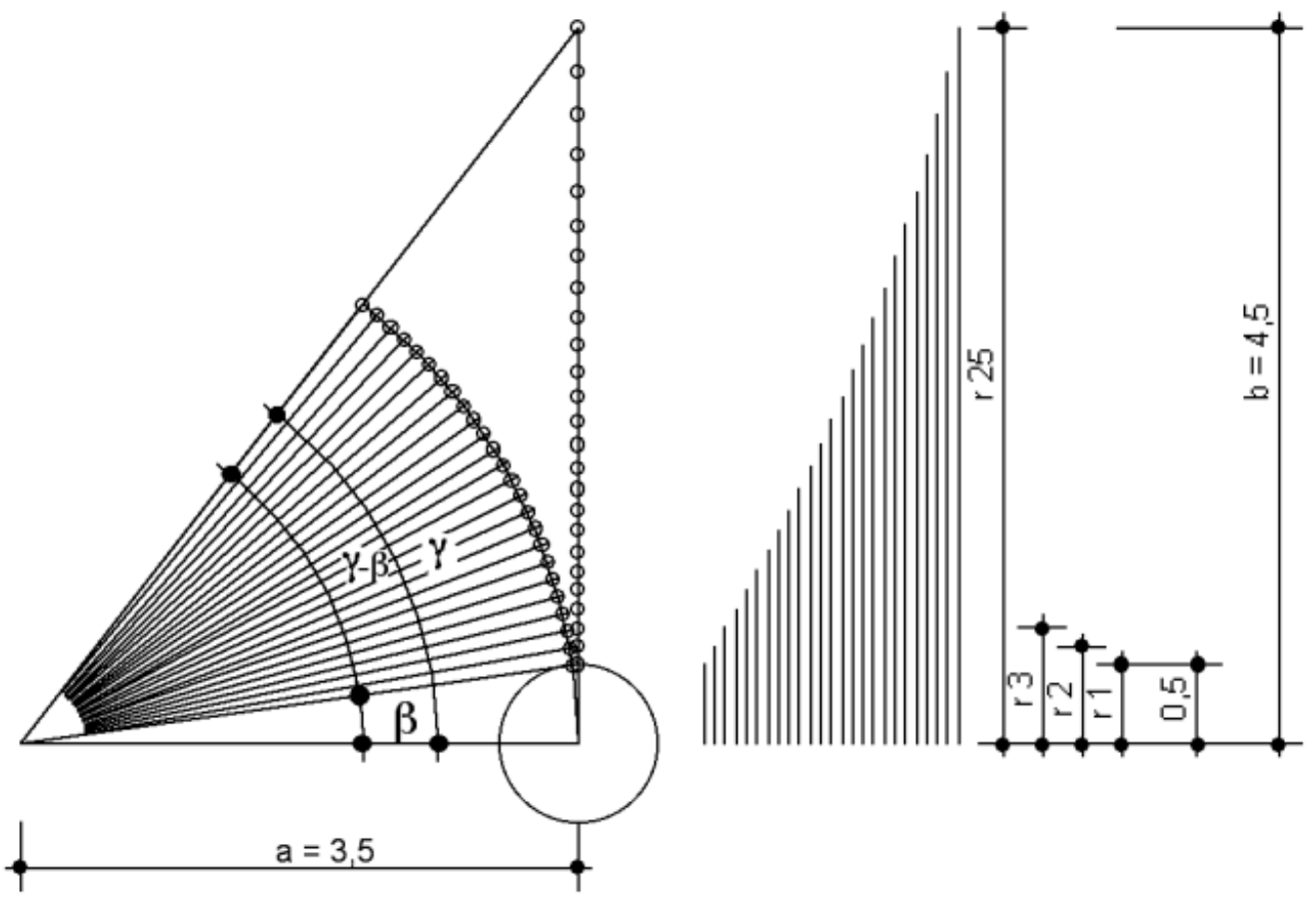

Fig. 6. The preparatory drawing of Philandrier. Drawing by the authors

At this point it is necessary to calculate the values of the radii beginning with angles $\gamma=\arctan \left(\frac{b}{a}\right)$ and $\beta=\arctan \left(\frac{0,5}{a}\right)$, obtaining: 


$$
\begin{aligned}
& r_{1}=0,5 \\
& r_{2}=3,5 \cdot \tan \left(\beta+\frac{\gamma-\beta}{24}\right) \\
& r_{3}=3,5 \cdot \tan \left(\beta+\frac{2 \cdot(\gamma-\beta)}{24}\right)
\end{aligned}
$$

and so forth. Generalizing for a whole $n$ between 1 and 25 (the circular arc is divided into 24 parts), we ascertain that the length of each radius is given by:

$$
r_{n}=3,5 \cdot \tan \left(\beta+\frac{(n-1) \cdot(\gamma-\beta)}{24}\right)
$$

The generating function of this construction is therefore a trigonometric function. It is important to note that even if formula (1) appears to be a function of the number of radii and not of the angles, this is not the case, since each radius corresponds to a precise and determined angle $r_{n} \leftrightarrow \pi / 2+n \cdot \pi / 4$.

In fact, it is possible to generalize formula (1) with a real number between $\pi / 2$ and $13 \pi / 2$, transforming the series $r_{n}$ into a continuous function: because the volute must be developed in three turns, we substitute the value of $6 \pi$ in place of 24 , while the factor $(n-1)$ with $n \in \mathrm{N}$, which indicates the rotation of $\pi / 4$ of the radii, is substituted by $(\alpha-\pi / 2)$ with $\alpha \in \mathrm{R}$. The equation in polar coordinates of the volute of Philandrier/Dürer will thus be:

$$
r(\alpha)=3,5 \cdot \tan \left(\beta+\frac{\left(\alpha-\frac{\pi}{2}\right)}{6 \pi}(\gamma-\beta)\right)
$$

The turns that the spiral makes before reaching the eye are defined as denominator of the argument with the value $6 p=3^{*} 2 \pi=3$ turns. An increase or decrease of this value makes the spiral make more or fewer turns, that is $k^{*} 2 \pi$ in the case of $k$ turns with $k \in \mathrm{N}$.

\section{Conclusions}

Studying the constructions in the original texts and then re-drawing them were fundamental steps in understanding the geometric characteristics of the different methods for constructing the volute and for preparing the analysis that followed, which was undertaken only if the construction showed itself to be capable of generalization. It is in fact clear that the methods examined here were the result of an inventive use of geometry with the aim of constructing curves that are derived from an interpretation of vague and diverse literary and archaeological sources. It is also clear that these methods were not developed with the intention of approximating any given mathematical curve.

In any case, if two methods were shown to be effectively only geometric constructions, which could certainly be approximated by means of functions but which were not themselves approximations of particular curves (neither by the intention of their creators nor in their characteristics), the third method showed characteristics that were interesting from a mathematical point of view as well.

44 Denise ANDREY AND MirKo Galli - Geometric Methods of the 1500s for Laying Out the Ionic Volute 
A careful analysis of the construction of Dürer that was adopted by Philandrier (whose merit it is solely to have introduced the eye of the volute) makes it evident that this is a method of constructing a spiral by points. The single points determined by this method belong to a transcendent curve generated by the tangent function, approximated then with circular arcs between the individual points. Further, the construction can be generalized, and the number of points can be increased so as to make it a continuous function in the limit. This type of spiral is not cited in the contemporary literature that we consulted, but we cannot forget that all functions of monotone growth on a certain interval are spirals in the polar plane. In this sense it is necessary to attribute to Dürer the invention of a method that is interesting from a geometrical point of view, and that uses, probably unintentionally, a trigonometric function.

Instead, Salviati and Serlio were not searching for a method for approximating spirals, but only for a way of laying out a drawing that would mediate between what academic studies of Vitruvius and direct studies of the ancient monuments brought to light. Geometrically speaking, Salviati and Serlio are interesting above all for the determination of the centers of the circular arcs (a problem derived from Vitruvius) that constitute the curve. The methods don't refer to any particular known spiral, but are only imitations of the idea of spirals, conceived to suit the Ionic volute, in contrast to that of Dürer, which was much more general. From a mathematical point of view we can affirm that they are constituted of three truncated Archimedean spirals, and that infinite continuous curves exist that are capable of approximating them in three complete turns. Their geometric nature does not permit generalizations, but it makes them easy to comprehend and immediately applicable. In particular, the construction of Salviati enjoyed an enormous success, and was republished in innumerable architectural treatises from the 1500 s to the $1800 \mathrm{~s}^{24}$

Translated from the Italian by Kim Williams

\section{Notes}

1. As late as 1837 the Allgemeine Bauzeitung, a journal for architecture and engineering published in Vienna, published an illustrated article in which five methods for laying out the Ionic volute precisely were explained and compared. See [Schwartz 1837].

2. The De Arquitectura Libri Decem of Vitruvius, the only work of architecture to come down to us from antiquity, was set out probably around 30 A.D. For a contemporary edition of Vitruvius see [Vitruvius 1997], which includes the essay of M. Losito that examines the various archaeological and literary sources and their interpretations.

3. Between the middle and the end of the Quattrocento Rome was the center of an intense program of study of antiquity promoted by Pope Leo X. The protagonists of this movement were Bramante, Simone Pollaiolo (called Cronaca) and Guiliano da Sangallo. The other vestiges of antiquity, strewn about the territory of the ancient empire (especially those outside Italy, but the ruins of Magna Grecia in Campania and Sicily as well) were unknown or ignored for a long time. See [Milton and Lampugnani 1994; Günther 1994; Agosti and Farinella 1997].

4. Temples in the Ionic style were built in Greece and Asia Minor from 550 B.C. onwards [Koch 1998, $10 \mathrm{ff}]$. The Romans used the Ionic order in varying kinds of public buildings-temples (see, for example, the Temple of Fortuna Virilis in Rome), baths, amphitheatres—as well as private buildings such as palazzi.

5. Deinde hae lineae dividantur ita, ut quattuor partes et dimidia sub abaco relinquantur. Tunc in eo loco, qui locus dividit quattuor et dimidiam et tres et dimidiam partem centur oculi conlocetur signeturque ex eo centro rotunda circinatio tam magna in diametro, quam una pars ex octo partibus est. Ea erit oculi magnitudine, et in ea catheto respondens diametros agatur [Vitruvius 1997, III: 256].

6. Tunc ab summa sub abaco inceptum, in singularis tetrantorum actionibus dimidiatum oculi spatium minuatur, deinde in eundem tetrantem qui est sub abaco veniat [Vitruvius 1997, III: 256]. 
7. $4.5-8^{*} 0.5=0.5$, which is the radius of the eye.

8. According to Mario Carpo, the other drawings cited in the Vitruvian text, ten in all, are all elementary geometric schemes rather than actual architectural elements [Carpo 1998, 22].

9. See [Ashby 1904], which discusses the so-called Coner Codex, a collection of sketches from Roman antiquity with very accurate dimensions, published in Rome presumably around 1515. A series of plates also presents various Ionic capitals, the volutes of which vary considerably from one to the other, but are usually of three revolutions.

10. See [Recht 2001] on the role of drawing as a means of bringing to life an ancient text and a centuries-old architectonic culture. See also [Carpo 1998] on the role played by print publication in the affirmation of drawing as a means of communicating ideas.

11. The Collins Dictionary Mathematics defines a spiral thus: "any plane curve formed by a point winding about fixed point at an ever-increasing distance from it..." [Collins 2002, 529].

12. Actually, this book, in spite of its denomination "Book IV", was the first published in the series that makes up Serlio's treatise.

13. L'occhio sia diviso in parti sei, e posto li numeri come si vede in figura si mette una punta del compasso sopra il numero 1 e l'altra punta sotto la cimasa, circuendo in giù fino al cateto... [Serlio 1537, 160].

14. See for example the Venetian editions of 1566 and 1588, which give the erroneous numeration. Instead, the German editions of Basel of 1609 gives the correct numeration.

15. However, the natural impulse is to trust the drawing, postulating some kind of error. It is possible, in fact, to construct an Ionic volute even from Serlio's "erroneous" construction; in order that the approximation of the spiral closes on the eye, it is necessary however to vary some of the dimensions given in both Serlio's and Vitruvius's texts. If we indicate, for example, the diameter of the eye as $\mathrm{d}_{0}$, then taking away the largest radius plus the "erroneous" dimunition of Serlio we obtain as a radius of minor length a radius of length:

$\left(4+1 / 6 d_{0}\right)-5 / 6 d_{0}-4 / 6 d_{0}-3 / 6 d_{0}-2 / 6 d_{0}-1 / 6 d_{0}=4-14 / 6 d_{0}$

Since, according to the construction, the last radius must be of a length $4 / 6 \mathrm{~d}_{0}$, we obtain a diameter $\mathrm{d}_{0}=4 / 3$ for the eye instead of 1 , as indicated by Vitruvius. Further, the volute would become larger $(8+4 / 9$ rather than 8$)$. Instead, by varying the size of the eye and the length of the first radius, we then obtain for the smaller radius:

$\left(4-\left[\left(\mathrm{d}_{0}-1\right) / 2\right]+1 / 6 \mathrm{~d}_{0}\right)-5 / 6 \mathrm{~d}_{0}-4 / 6 \mathrm{~d}_{0}-3 / 6 \mathrm{~d}_{0}-2 / 6 \mathrm{~d}_{0}-1 / 6 \mathrm{~d}_{0}=4+1 / 2-17 / 6 \mathrm{~d}_{0}$ Setting again the minor radius equal to $4 / 6 \mathrm{~d}_{0}$ we obtain a diameter of the eye $\mathrm{d}_{0}=9 / 7$.

16. [Alberti 1483: VII, viii]. The larger circle measures 8 units, the eye 1 unit. The center of the eye is lower by 1 unit with respect to the center of the larger circle. There are two points in which the compass is placed alternately: the upper and lower points of the eye, beginning with the upper. Since the radius of the half-circumference decreases by 1 unit every time, with the first radius being 4 , after four operations the arcs end on the eye and the volute is complete. The volute has only two turns and the distance between them remains constant. In this the solution adapts itself well to the hypothetical volute of Vitruvius, leaving aside a critical comparison with the ruins of antiquity. It is interesting, however, to note the simplicity of the Albertian method, in which can be recognized in part the inspiration for Serlio.

17. [Kruft 1998, 35]. Alberti wrote in Latin for a cultured, humanistic readership. His text was initially published without illustrations. The edition princeps of 1485 (but the treatise was already completed by 1452, before Alberti would undertake actual building projects) did not have any figures. The first illustrated edition was the Florentine edition of 1550, edited by Cosimo Bartoli. The drawing of the Ionic volute in this edition appears, after careful examination, to be wrong: the eye is positioned lower than it should be. Only a reading of the text clarifies its position.

18. ...sarà il congiungimento dell'un arco con l'altro parallelo con il suo centro allato [accanto] del seguente quarto [Salviati 2000: 106].

19. It should be noted that the method developed by Salviati is approximate as well. In fact, if we try to follow his directions and try all the centers of the twelve quarter-circles according to his rules (using a modern CAD program), we discover that they are not only located on the diagonals of a square, but

46 Denise ANDREY AND MirKo Galli - Geometric Methods of the 1500s for Laying Out the Ionic Volute 
that they are slightly rotated. We have, however, decided to base our analysis solely on the directions given in the original text.

20. This work enjoyed great fortune and numerous successive editions were published; see [Lemerle 2000], a facsimile publication of the edition published in Lyon in 1552, which also includes a rich critical apparatus.

21. Dürer gives no indication as to how he developed the methods he presents. An interesting comment on the text can be consulted on the Internet, at the URL http://www.mathe.tufreiberg.de/ hebisch/cafe/duerer/spiralen.html.

22. Naturally, an algebraic calculation is possible, even if in the case of Salviati it is rather lengthy, due to the recursive application of the Pythagorean theorem with irrational values. For Serlio's construction this is very simple: the length of the radius is derived directly from the rules for setting out.

23. For Salviati, we have $a=80 / 10000, b=364 / 10000$ and $c=4291 / 10000$; for Serlio $a=80 / 10000$, $b=$ $354 / 10000$ and $c=4404 / 10000$.

24. Serlio's construction was abandoned after some time, while the others were taken up again and again in successive publications. The generation of a complete list of the use of the methods of Salviati and Dürer/Philandrier on the part of architectural theorists who have studied this is beyond the scope of the present paper. Perhaps it is most interesting to point out that in his Vollständige Anweisung zu der Civil-Bau-Kunst [1696], Nikolaus Goldmann (Dutch, 1632-1665) developed a yet another method, based on an equilateral triangle with a vertex in the center of the eye and the opposite side tangent to the eye; however, we have not examined here because it came about in a later cultural context. This method was taken up in particular by the English theorist James Gibbs (1682-1754) and by William Chambers (1723-1796); see [Chambers 1825, pl. 9, "Goldmann volute"]. The three methods are set out next to one another in [D’Avilier 1760, pl. 21, 22, 23]. The plate illustrating Salviati's method is particularly detailed, and contains the explanation relative to the necessity that two successive centers are found on the same straight line.

\section{References}

Agosti, G. and V. Farinella, eds. 1997. Michelangelo. Studi sull'antichità dal Codice Coner. Turin: UTET.

AlberTi, Leon Battista, 1483. De Re Aedificatoria. Florence.

AsHby, T. 1904. Sixteenth-century drawings of Roman buildings attributed to Andreas Coner. In Papers of the British school at Rome, vol. II. London: Macmillan.

CARPO, M. 1998. L'architettura nell'età della stampa. Milan: JakaBook.

CHAMBers, W. 1825. A treatise on the decorative part of civil architecture. London: Priestley and Weale.

D'Avilier, Augustin-Charles. 1760. Cours d'architecture qui comprend les Ordres de Vignole. Nouvelle édition enrichie de nouvelles planches. Paris: Pierre-Jean Mariette.

Collins Dictionary Mathematics. 2002. Glasgow: HarperCollins.

DesgodetZ, A. 1682. Les Edifices Antiques de Rome. Paris.

DÜRER, A. 1525. Underweysung der Messung mit dem Zyrckel und Richtscheyt. Nurimberg.

Forsmann, E. 1988. Ionico, Dorico, Corinzio nell'architettura del Rinascimento. Bari: Laterza.

Goldmann, Nikolaus. 1696. Vollständige Anweisung zu der Civil-Bau-Kunst. Wolfenbüttel. (published posthumously by Leonhard Christoph Sturm).

GÜNTHER, H. 1994. La rinascita dell'antichità. Pp. 259 ff. in Rinascimento da Brunelleschi a Michelangelo. H. Milton and V. M. Lampugnani, eds. Milan: Bompiani.

KRUfT, H.W. 1998. Storia delle teorie architettoniche. Da Vitruvio al Settecento. Bari: Laterza.

JoHST, Chistopher. 1994. Lo studio dell'antico. Pp. 425 ff. in Rinascimento da Brunelleschi a Michelangelo, H Milton and V. M. Lampugnani, eds. Milan: Bompiani.

KoCH, W. 1998. Baustilkunde. Gütersloh: Bertelsmann.

Lemerle, F. 2000. Les annotations de Guillaume Philandrier sur le De Arquitectura de Vitruve. Paris: Picard.

LOSiTO M. 1997. La ricostruzione della voluta del capitello ionico vitruviano nel Rinascimento italiano. Pp. 1409 ff. in Vitruvius, De arquitectura, P. Gros, ed. Turin: Einaudi. 
Milton, H. and V. M. Lampugnani, eds. 1994. Rinascimento da Brunelleschi a Michelangelo. Milan: Bompiani.

PALladio, A. 1570. I quattro libri dell'architettura. Venice.

Philandrier, G. 1544. Gulielmi Philandri Castilionii in decem libros M. Vitruvii Pollionis de Arquitectura Annotationes. Rome.

RECHT, R. 2001. I/ disegno di architettura. Milan: Jaka Book.

SALVIATI, G. 1552. Regola di far perfettamente col compasso la voluta jonica et del capitello ionico et d'ogni altra sorte. Venice.

1814. Regola di far perfettamente col compasso la voluta jonica et del capitello ionico et d'ogni altra sorte. In G. Selva, La Voluta Jonica, Padua.

2000. Regola di far perfettamente col compasso la voluta jonica et del capitello ionico et d'ogni altra sorte. E. Balistreri, ed. Venice: Cetid.

SCAMOZZI, V. 1615. L'idea dell'architettura universale. Venice.

SERLIO, S. 1537. Regole generali di architettura sopra le cinque maniere degli edifici (...) con gli esempi delle antichità che, per la magior parte, concordano con la dottrina di Vitruvio. Venice.

SCHWARZ, G. 1837. Die Schneckenlinie des ionischen Säulenkapitäls. Allgemeine Bauzeitung: 76-82; 88-93; tav. CXIII.

Vignola, J. Barozzi da. 1562. Regola delli Cinque Ordini di Architettura. Roma.

VITRUVIUS. 1997. De arquitectura. P. Gros, ed. Turin: Einaudi.

\section{About the Authors}

Denise Andrey was born in 1969 and earned her degree in mathematics in Zurich in 1995. Since 1999 she has been an assistent in mathematics at the Accademia di architettura of Mendrisio, Switzerland. Her principle interests are the history of mathematics and mathematical modelling of urban development. She lives in Lugano.

Mirko Galli was born in 1969, and earned a degree in architecture from the ETH of Zurich in 1995. In addition to practicing architecture, he teaches, and writes criticism and research of a historical-architectural nature. He is the author of various articles and essays concerning this history of architecture. He lives and works in Lugano. 